\title{
The influence of low back pain on health - related quality of life and the impact of balneal treatment
}

\section{STANCIU Liliana-Elena ${ }^{1,2}$, PETCU Lucian Cristian ${ }^{2}$, APOSTOL Sterian ${ }^{1,2}$, IONESCU Elena-Valentina ${ }^{1,2}$, OPREA Doinița ${ }^{1,2}$, OPREA Carmen ${ }^{1,2}$, ȚUCMEANU Elena-Roxana ${ }^{1,2}$, ILIESCU Mădălina-Gabriela ${ }^{1,2}$, POPESCU Marius-Nicolae ${ }^{4}$, OBADA Bogdan ${ }^{1,3}$}

Editor: Constantin Munteanu, Romanian Association of Balneology,office@bioclima.ro Reviewers: Dogaru Gabriela and Rotariu Mariana

*Corresponding author: STANCIU Liliana-Elena, e-mail: lilianastanciu77@yahoo.com

1 Faculty of Medicine, „Ovidius” University of Constanta, Romania

2 Department of Rehabilitation, Balneal and Rehabilitation Sanatorium of Techirghiol, Constanta, Romania

3 St. Andrew Emergency County Clinical Hospital of Constanta, Romania

4 "Carol Davila" University of Medicine and Farmacy, Bucharest, Romania

\section{Abstract}

Introduction. Low back pain has a direct and proportional impact on function and a general one on the quality of life. The present study aims to evaluate the functional impact of low back pain using specific self-assessment tools as indexes of appreciation and epidemiological correlations of potential risk factors involved. The conceptual model of our research is based on the importance of correlating symptoms with clinical assessment, using scales of pain, disability, quality of life, and determination of epidemiological correlations of these areas and the determined factors of the pathology.

Material and method. The study group is made up of 106 cases with clinical diagnostic of low back pain, admitted from 28 September 2020 to 28 March 2021, at Balneal and Rehabilitation Sanatorium of Techirghiol. After performing anamnesis, general clinical examination, specific neuro-musculo-skeletal examination, the patients filled the surveys highlighting the impact of their low back pain on functionality and disability deriving from it. The survey included the Oswestry Disability Index, the Functional Independence Measure (FIM) instrument and the Visual analog scale (VAS) score evaluated at the moment of hospitalization and at discharge. Statistical analysis of data was carried out and correlations between variables resulting from study were highlighted. The study was conducted according to the norms of deontology and medical ethics. The authors declare no conflict of interest.

Results and discussions. Lumbar pathology is common in patients who are hospitalized for a complex balneary-physical-kinetic treatment at Balneal and Rehabilitation Sanatorium of Techirghiol. About $80 \%$ of patients who have addressed to our unit in which the study was conducted, have presented low back pain. The majority of patients were females, representing $57,55 \%$ of the total number. Regarding the patients' age, 58,5\% of them were in the 50-70 years interval. The study reveals a major positive impact of our treatment on spinal symptomatology, an effect pointed out by the relevant statistical differences between the admittance and discharge VAS scores $(\mathrm{p}<0.001)$. Reporting the investigated disability with the Oswestry questionnaire of painful lumbar syndrome, and functional evaluation scale (FIM) demonstrates the impact of this pathology on the patient's social life, once again emphasizing the special attention to be paid to axial pathology, both as curative treatment and the importance of prophylactic treatment. Statistical analysis of identified risk factors, reveals the importance of prophylaxis and patient's education in this area. A strong and important statistical correlation was found between the Oswestry total score and the walking and standing items, and a moderate, but strong correlation with the other items. Regarding the sex life item, the correlation is existent, but at a modest level.

Conclusions. The study reveals the importance of correlation of the data obtained from anamnesis, the general clinical examination and the specific examination neuromioarthrokinetic with assessment tools that determine the level of functional independence, the functional impact on social life in high-frequency pathologies treated in medical facilities that provide healthcare in the field of medical recovery. It is necessary to quantify the therapeutic results obtained, in order to assess the level of improvement in quality of life..

Keywords: low back pain, balneal, functional indicators, quality of life,

\section{INTRODUCTION}

Low back pain is a very common symptom. It occurs in high-income, middle-income, and low-income countries and all age groups from children to the elderly population. Globally, years lived with disability caused by low back pain increased by $54 \%$ between 1990 and 2015, mainly because of population increase and ageing, with the biggest increase seen in low-income and middleincome countries (1-3). Low back pain is now the leading cause of disability worldwide.

Low back pain has a direct and proportional impact on function and a general one on the quality of life. The present study aims to evaluate the functional impact of low back pain using specific self-assessment tools as indexes of appreciation and epidemiological correlations of potential risk factors involved. The conceptual model of our research is based on the importance of correlating 
symptoms with clinical assessment, using scales of pain, disability, quality of life, and determination of epidemiological correlations of these areas and the determined factors of the pathology (4).

The Orthopedic Section of the American Physical Therapy Association (APTA) has an ongoing effort to create evidence-based practice guidelines for orthopedic physical therapy management of patients with musculoskeletal impairments described in the World Health Organization's International Classification of Functioning, Disability, and Health (ICF).

\section{Material and method}

The study group is made up of 106 cases with clinical diagnostic of low back pain, admitted from 28 September 2020 to 28 March 2021, at Balneal and Rehabilitation Sanatorium of Techirghiol. After performing anamnesis, general clinical examination, specific neuro-musculoskeletal examination, the patients filled the surveys highlighting the impact of their low back pain on functionality and disability deriving from it. The survey included the Oswestry Disability Index, the Functional Independence Measure (FIM) instrument and the Visual analog scale (VAS) score evaluated at the moment of hospitalization and at discharge. Statistical analysis of data was carried out and correlations between variables resulting from study were highlighted.

The Oswestry Disability Index (ODI) has been developed to assess pain-related disability in people with acute, subacute, or chronic low back pain. Since it was first published in 1980, several different versions have been developed The ODI covers 1 item on pain and 9 items on activities of daily living (personal care, lifting, walking, sitting, standing, sleeping, sex life, social life, and traveling), making a total of 10 items. The ODI has adequate content validity, as it covers activities of daily living that are commonly experienced by patients with back pain. However, it lacks generic activities such as work, leisure, recreation, or sporting activities. The ODI has high internal consistency, with Cronbach's alpha between 0.71 and 0.87 . It correlates with other measures of disability, such as the Roland-Morris Disability Questionnaire (RDQ) and shows moderate correlation with pain scales and the Short Form. Administration of the ODI questionnaire over the phone has excellent testretest reliability when compared to face-to-face administration. Telephone administration is a convenient and reliable option for obtaining follow-up outcomes data. Telephonic administration of the ODI is scientifically valid and should be an accepted method of data collection for state-level and national-level outcomes projects (5-7).

The Functional Independence Measure (FIM) score is just one of many tools that clinicians can use to determine independence or amount of assistance needed in a rehabilitation setting as well as after discharge. The
FIM was also developed to offer a uniform system of measurement for disability based on the International Classification of Impairment, Disabilities and Handicaps for use in the medical system in the United States (McDowell \& Newell, 1996). The FIM assesses six areas of function (Self-care, Sphincter control, Transfers, Locomotion, Communication and Social cognition), which fall under two Domains (Motor and Cognitive). It has been tested for use in patients with stroke, traumatic brain injury, spinal cord injury, multiple sclerosis, and elderly individuals undergoing inpatient rehabilitation and has been used with children as young as 7 years old. The FIM consists of 18 items assessing 6 areas of function. The items fall into two domains: Motor (13 items) and Cognitive (5 items). The motor items are based on the items of the Barthel Index. These domains are referred to as the Motor-FIM and the Cognitive-FIM (8).

The patients admitted underwent specific rehabilitation treatment which included a wide range of therapies. All patients received balneotherapy with the use of the local natural sources - the mineral water of the lake Techirghiol and also peloid therapy using the sapropelic mud extracted from the bottom of the lake. Electrotherapy varied from low, medium and high frequency electrical currents. The patients also underwent kinetotherapy and kinesiotherapy with the assistance of specialized physiotherapists

\section{Results}

Lumbar pathology is common in patients who are hospitalized for a complex balneal-physical-kinetic treatment at Balneal and Rehabilitation Sanatorium Techirghiol

The majority of patients were females, representing $57,55 \%$ of the total number. Regarding the patients' age, $58,5 \%$ of them were in the $50-70$ years interval.

\section{Table 1 - Total Score Oswestry Questionnaire - Spearman's rho}

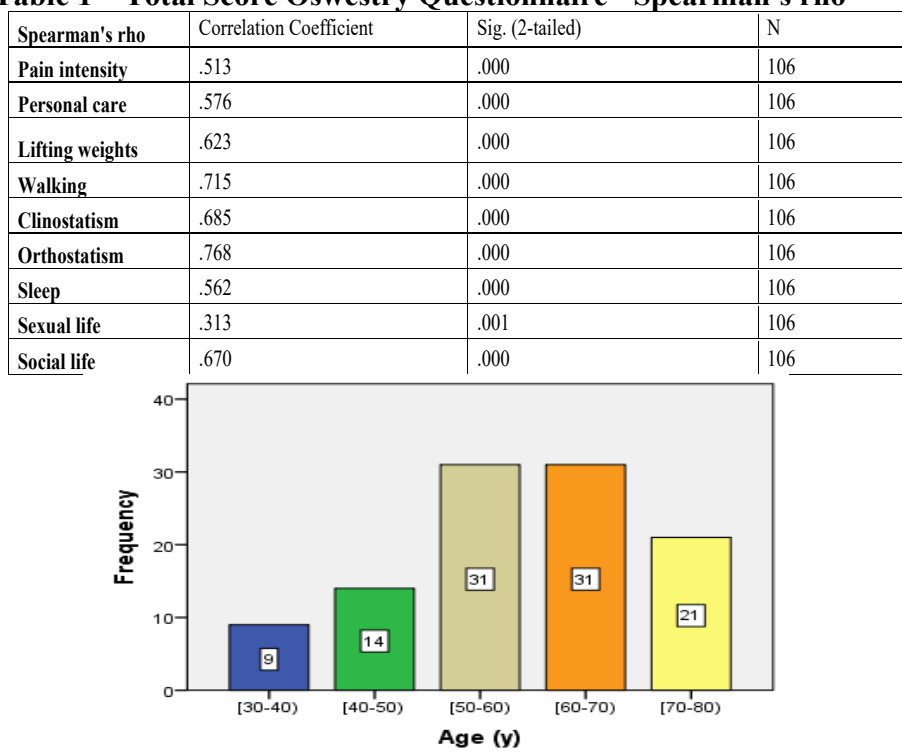

Graph 1 - Age interval distribution 
Regarding the urban/rural distribution- $74,53 \%$ of the patients were from urban areas, perhaps also due to the easier accessibility to medical services, in general The study reveals a major positive impact of our treatment on spinal symptomatology, an effect pointed out by the relevant statistical differences between the admittance and discharge VAS scores $(\mathrm{p}<0.001)$.

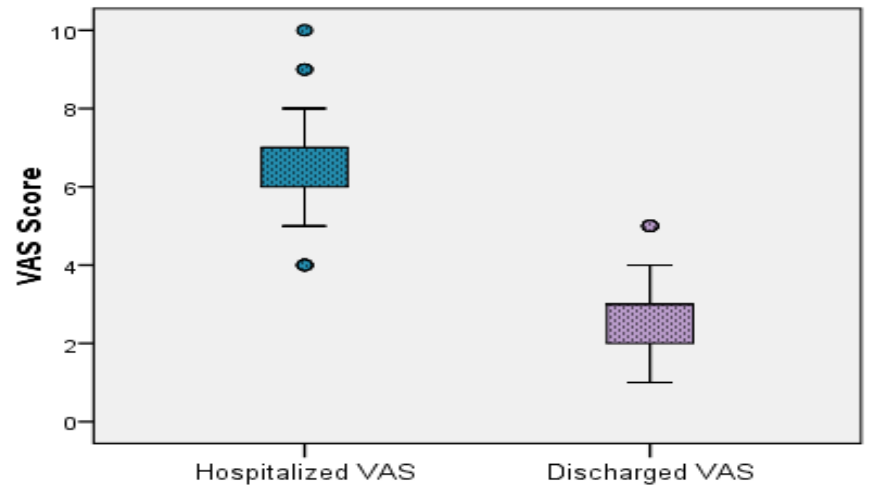

Graph 2 - Box-Plot representation of the distribution of VAS scores at admission and VAS at discharge

There are significant differences between median VAS scores at admission and discharge $(\mathrm{p}<0,001$, Wilcoxon signed-rank test). Admission VAS scores were higher than discharge VAS scores.

Reporting the investigated disability with the Oswestry questionnaire of painful lumbar syndrome, and functional evaluation scale (FIM) demonstrates the impact of this pathology on the patient's social life, once again emphasizing the special attention to be paid to axial pathology, both as curative treatment and the importance of prophylactic treatment. Statistical analysis of identified risk factors reveals the importance of prophylaxis and patient's education in this area.

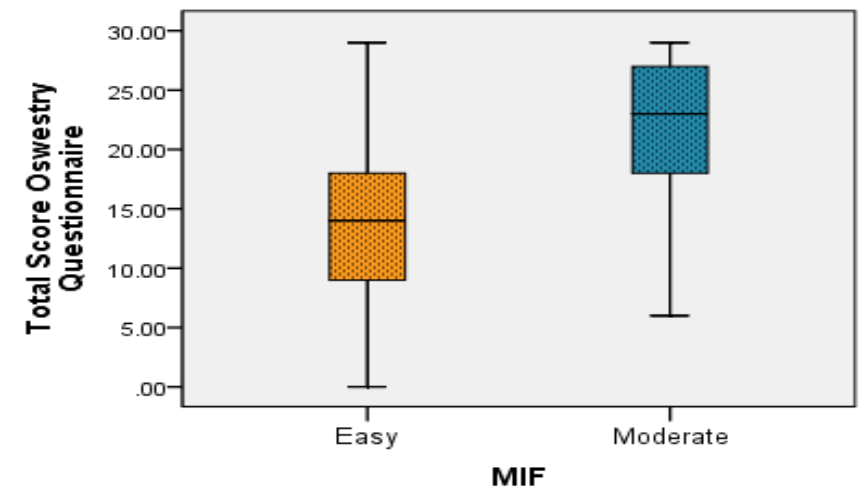

Graph 3 - Box-Plot representation of the distribution of MIF and Oswestry Total Score Questionnaire

A strong and important statistical correlation was found between the Oswestry total score and the walking and standing items, and a moderate, but strong correlation with the other items. Regarding the sex life item, the correlation is existent, but at a modest level.

There are significant differences between the median values of the Oswestry scores corresponding to the three groups Walking $[0-2) /[2-4] /[4-5]] \quad(\mathrm{p}=0 \quad<0,05$, Independent Samples Median test).

The distribution of scores Oswestry differed in the Walking $[0-2] /[2-4] /[4-5]]$ groups, scores Oswestry were higher in the Walking [4-5] group than in the Walking [02] and Walking [2-4]] groups

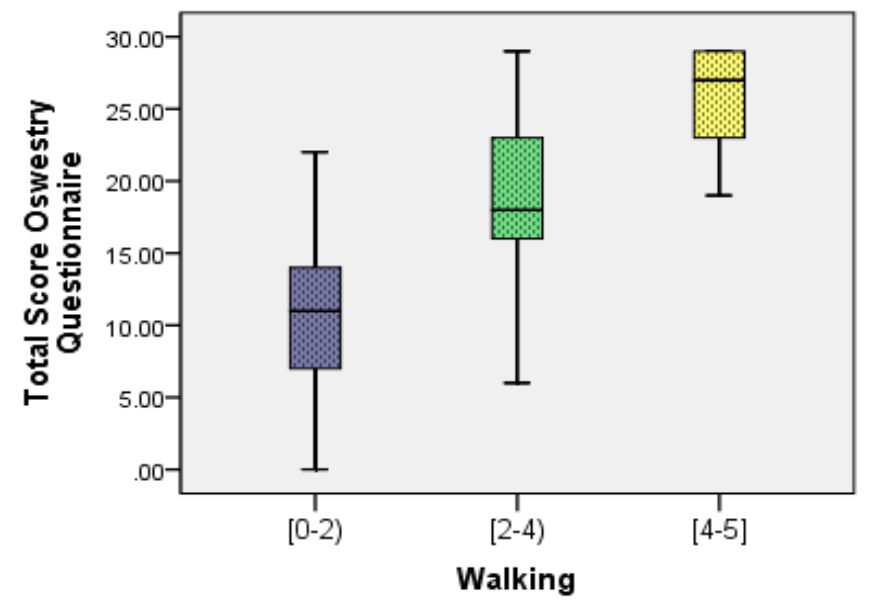

Graph 4 - Box-Plot Representation of Oswestry Questionnaire Total Score Distribution and movement There are significant differences between the median values of the Oswestry scores corresponding to the three groups Clinostatism [0-2)/[2-4]/[4-5]] ( $\mathrm{p}=0<0,05$, Independent Samples Median test).

The distribution of scores Oswestry is different in the three Clinostatism groups $[0-2) /[2-4] /[4-5]]$, the Oswestry scores were higher in the Clinostatism [4-5] group than in the Clinostatism [0-2) and Clinostatism [2-4)] groups.

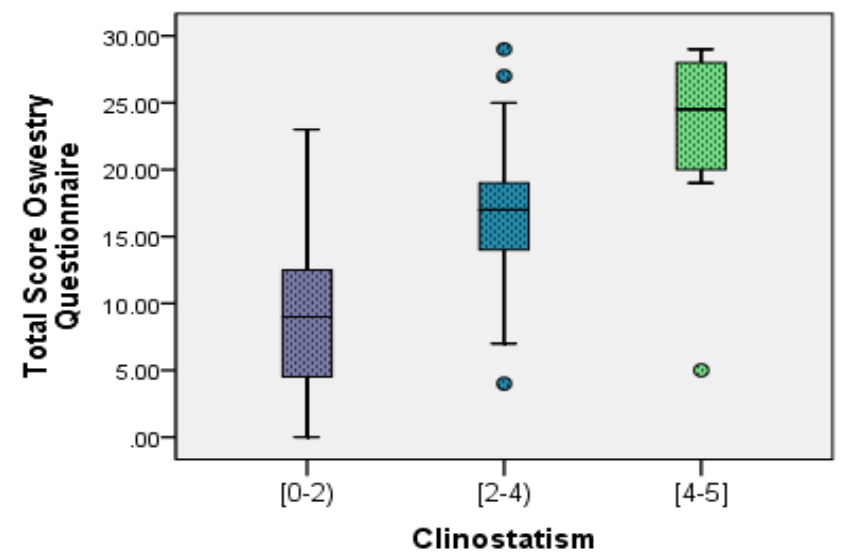

Graph 5 - Box-Plot Representation of Oswestry Questionnaire Total Score Distribution and Clinostatism There are significant differences between the median values of the Oswestry scores corresponding to the three groups Orthostatism [0-2)/[2-4]/[4-5]] $(\mathrm{p}=0<0,05$, Independent Samples Median test).

The distribution of scores Oswestry is different in the three Orthostatism groups $[0-2) /[2-4] /[4-5]]$, the Oswestry scores were higher in the Orthostatism [4-5] group than in the Orthostatism[0-2) and Orthostatism [24)] groups. 


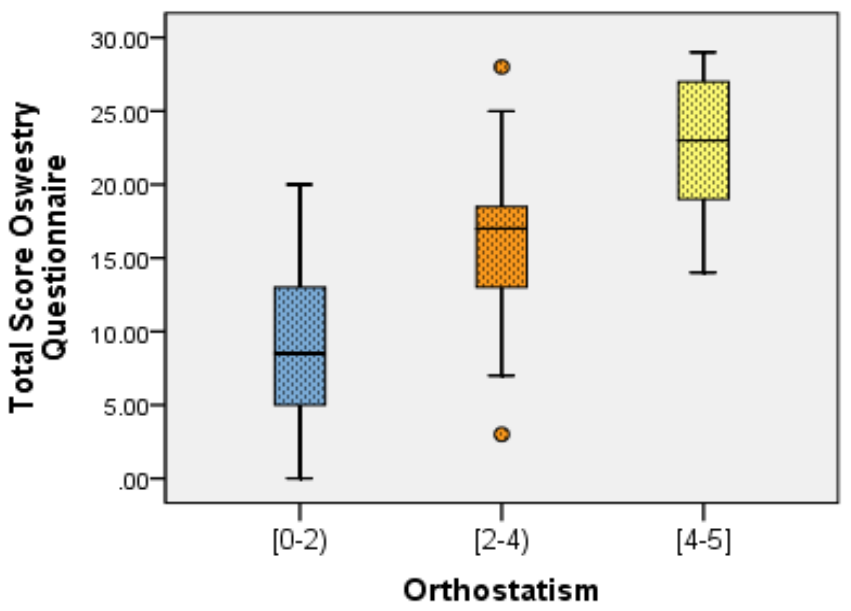

Graph 6 - Box-Plot Representation of Oswestry Questionnaire Total Score Distribution and Standing

There are significant differences between median Oswestry values, corresponding to the two groups Sleep $[0-2) /[2-4)(p=0<0,05$, Independent Samples Median test).

The distribution of scores Oswestry differed in the two Sleep $[0-2) /[2-4)]$ groups, scores Oswestry were higher in the Sleep [2-4)] group, with values ranging from 15-20, than in the Sleep [0-2)] group, with values ranging from $6-17$

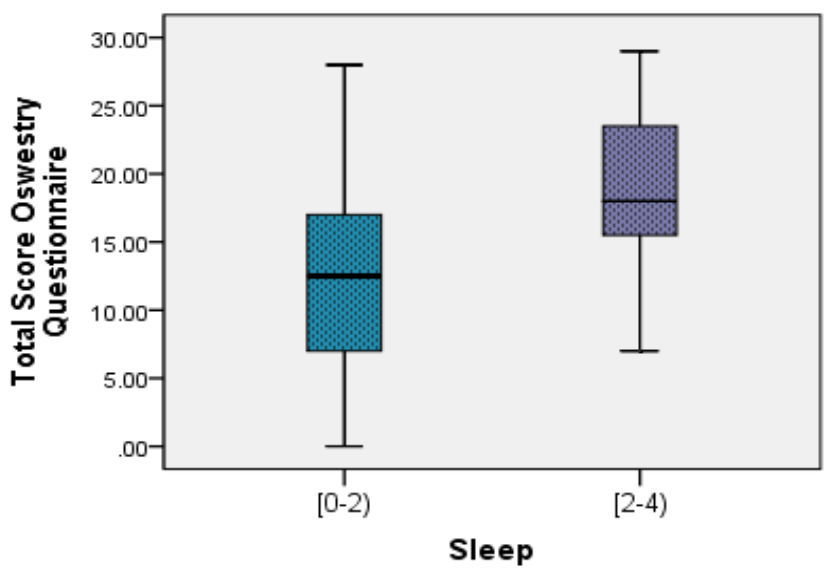

Graph 7 - Box-Plot Representation of Oswestry Questionnaire Total Score Distribution and Sleep

There are significant differences between median Oswestry values, corresponding to the two groups Sexual Life $[0-2) /[2-4) \quad(p=0<0,05$, Independent Samples Median test).

The distribution of scores Oswestry is different in the two Sexual Life groups [0-2)/[2-4)], scores Oswestry were higher in the Sexual Life [2-4) group, with values ranging from 18-28, than in the Sexual Life [0-2) group, with values ranging from 9-18.

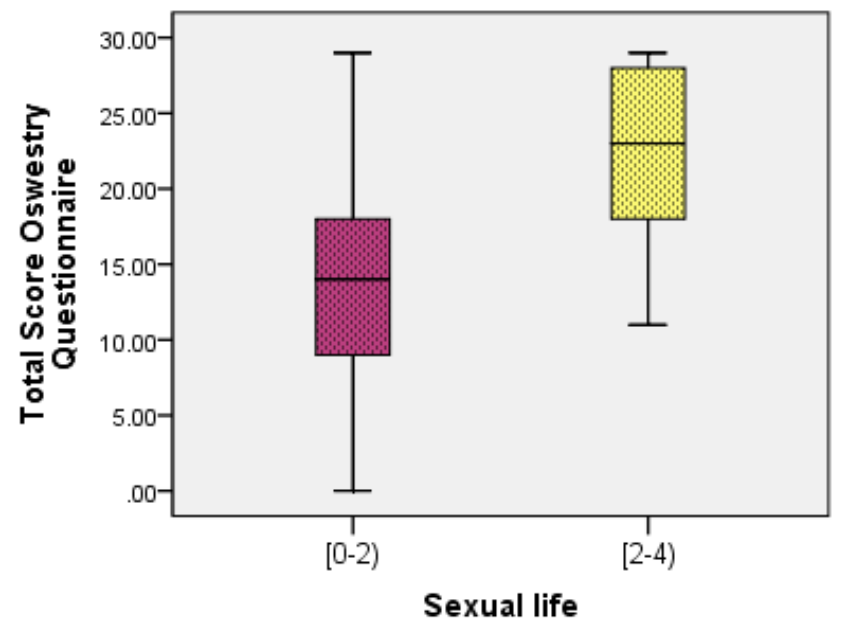

Graph 8 - Box-Plot Representation of Oswestry

Questionnaire Total Score Distribution and Sexual Life There are significant differences between the median values of the Oswestry scores corresponding to the three groups Social Life $[0-2) /[2-4] /[4-5]](p=0<0,05$, Independent Samples Median test).

The distribution of scores Oswestry is different in the three Social Life groups $[0-2) /[2-4] /[4-5]]$, the Oswestry scores were higher in the Social Life[4-5] group than in the Social Life [0-2) and Social Life [2-4)] groups.

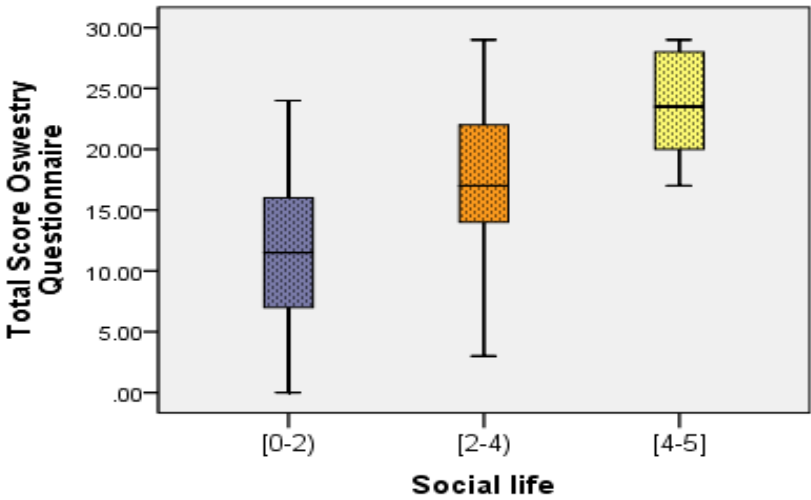

Graph 9 - Box-Plot Representation of Oswestry Questionnaire Total Score Distribution and Social Life

There are significant differences between median Oswestry values, corresponding to the two groups Travels $[0-2) /[2-4)(\mathrm{p}=0<0,05$, Independent Samples Median test).

The distribution of scores Oswestry differed in the two Travels [0-2)/[2-4)] groups, scores Oswestry were higher in the Travels [2-4)] group, with values ranging from 1523 , than in the Travels [0-2)] group, with values ranging from 5-15. 


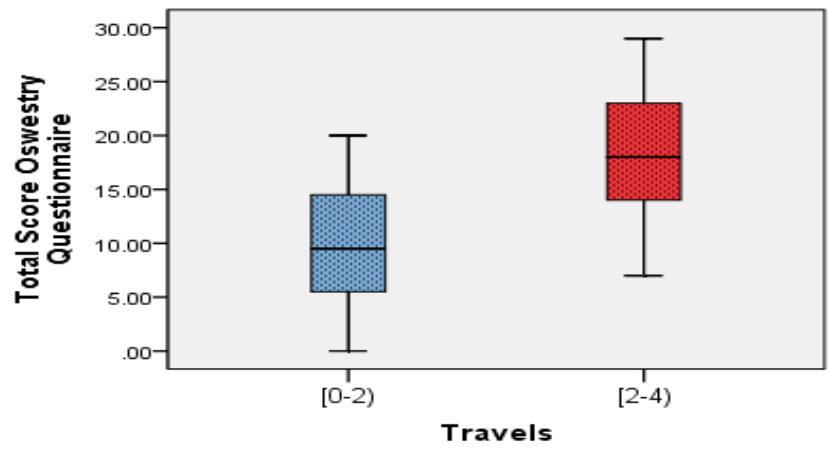

Graph 10 - Box-Plot representation of the distribution of the Oswestry Questionnaire Total Score and Travels

There are significant differences between median Oswestry values, corresponding to the two groups Pain intensity $[0-2) /[2-4) \quad(p=0,001<0,05$, Independent Samples Median test).

The distribution of Oswestry scores differed in the two Pain intensity [0-2)/[2-4)] groups ( $p<0,001$, Independent Samples Mann-Whithney U test), Oswestry scores were higher in the Pain intensity [2-4)] group than in the Pain intensity [0-2)] group

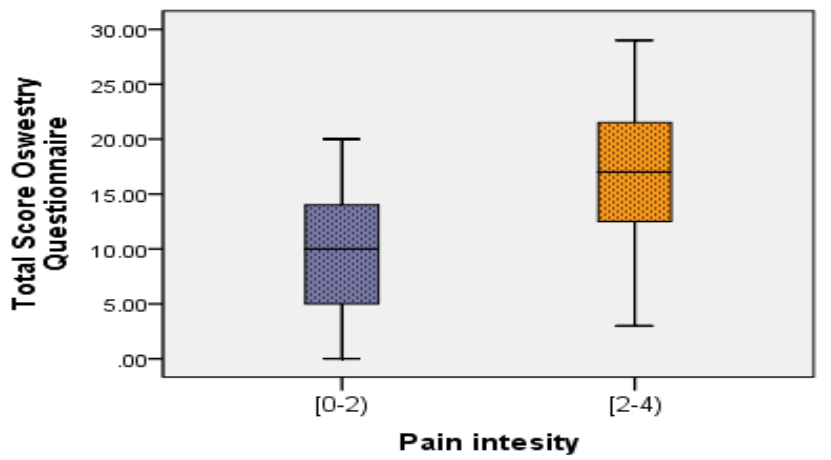

\section{Graph 11 - Box-Plot representation of the distribution of Oswestry Total Score Questionnaire and pain intensity}

\section{Discussions}

The results show a clear predominance of low back pain in female patients as opposed to males, which needs to be addressed if it has true gender preponderance or is given by a population disbalance in favor of more females than males (4,9-12). As we can see, the age distribution is mostly in late adulthood and early elderhood, but nevertheless the balance is towards more advanced age, clearly suggesting a degenerative problem (13). Almost three quarters of the patients come from urban setting, which is due most likely to the access to medical services, as opposed to rural population who, by the nature of rural lifestyle, should have a distribution in accordance with rural/urban general distribution.

During the hospitalization period, with the help of the specific rehabilitation therapies, we observed a clear reduction of the algic syndrome, a thing that was reported by all patients by the means of the common VAS pain score. As the pain subsided, the general mobility has improved, with a direct influence over the overall functionality (14), as shown by the functional evaluation scale, indicating that the balneotherapy and the usage of physical therapy might be useful as a prophylactic treatment, not only as curative treatment $(15,16)$.

After analyzing the distribution of the total Oswestry score and comparing it with each individual item, we observe that low back pain affects proportionally each aspect of the patient life. Similar distributions of the patients in 3 groups were found for the walking, standing, lying down and social life, and in 2 groups for sleeping, sexual life, travelling, and pain intensity. We know that a cause of insomnia is chronic pain, and we observed an improvement of the quality in sleep as we managed to decrees the pain felt in LBP syndrome $(17,18)$, and it should be monitored on a longer period of time to verify if it is a consistent improvement. We should take into consideration the specific socio-economical factors of the Romanian nationality patients when analyzing some aspects of the everyday life such as sexual life (19) which has shown a clear improvement, but still with a notable dissatisfaction (from social viewpoint, as there is certain stigma about this essential aspect of life) and travelling (from the economical perspective, is quite prohibitive), which also showed a statistically relevant improvement(20). The clearest affliction is observed at patients in standing position, where they felt it has the greatest impact of the overall quality of life in comparison with all the other aspects of life (21). We can also see that the patients had a more direct approach when it comes the pain intensity with either considering the pain to be a big problem or a small nuisance that they could live with it, aspects shown in many other clinical studies from this field (22-26).

\section{Conclusions}

The study reveals the importance of correlation of the data obtained clinical exam with self-assessment tools, that determine the level of functional independence and the functional impact on social life. It is necessary to quantify the therapeutic results obtained, in order to assess the level of improvement in quality of life.

Low back pain (LBP) is the second leading cause of disability in the world. The level of disability in patients with LBP is an important outcome measure for clinical practice and research $(27,28)$. The Oswestry Disability Index (ODI) is one of the most commonly used scales that assess the disability related to LBP.

\section{References}

1. Andersson GB. Epidemiological features of chronic lowback pain. Lancet. 1999;354(9178):581-585. doi:10.1016/S0140-6736(99)01312-4.

2. Pieber K, Stein KV, Herceg M, Rieder A, Fialka-Moser V, Dorner TE. Determinants of satisfaction with individual health in male and female patients with chronic low back pain. J Rehabil Med. 2012;44(8):658-663. doi:10.2340/16501977-1010 
3. Ganesan S, Acharya AS, Chauhan R, Acharya S Prevalence and Risk Factors for Low Back Pain in 1,355 Young Adults: A Cross-Sectional Study. Asian Spine J. 2017;11(4):610-617. doi:10.4184/asj.2017.11.4.610

4. Zaina F, Balagué F, Battié M, Karppinen J, Negrini S. Low back pain rehabilitation in 2020: new frontiers and old limits of our understanding. Eur J Phys Rehabil Med. 2020;56(2):212-219. doi:10.23736/S1973-9087.20.06257-7

5. Sheahan PJ, Nelson-Wong EJ, Fischer SL. A Review of Culturally Adapted Versions of the Oswestry Disability Index: The Adaptation Process, Construct Validity, TestRetest Reliability and Internal Consistency. Disabil Rehabil. 2015;37:2367-74.

6. Fairbank JC, Pynsent PB. The Oswestry Disability Index. Spine (Phila Pa 1976). 2000;25(22):2940-2952. doi:10.1097/00007632-200011150-00017

7. Chin-Pang Lee, Tsai-Sheng Fu, Chia-Yih Liu, Ching-I Hung, Psychometric evaluation of the Oswestry Disability Index in patients with chronic low back pain: factor and Mokken analyses, Health and Quality of Life Outcomes volume 15, Article number: 192 (2017)

8. Wright J. (2011) Functional Independence Measure. In: Kreutzer J.S., DeLuca J., Caplan B. (eds) Encyclopedia of Clinical Neuropsychology. Springer, New York, NY. https://doi.org/10.1007/978-0-387-79948-3_1810

9. Wettstein M, Eich W, Bieber C, Tesarz J. Pain Intensity, Disability, and Quality of Life in Patients with Chronic Low Back Pain: Does Age Matter?. Pain Med. 2019;20(3):464-475. doi:10.1093/pm/pny062

10. Bingefors K, Isacson D. Epidemiology, co-morbidity, and impact on health-related quality of life of self-reported headache and musculoskeletal pain--a gender perspective. $\begin{array}{lll}\text { Eur J } & \text { Pain. 2004;8(5):435-450. }\end{array}$ doi:10.1016/j.ejpain.2004.01.005

11. Meucci RD, Fassa AG, Faria NM. Prevalence of chronic low back pain: systematic review. Rev Saude Publica. 2015;49:1. doi:10.1590/S0034-8910.2015049005874

12. Violante FS, Mattioli S, Bonfiglioli R. Low-back pain. Handb Clin Neurol. 2015;131:397-410. doi:10.1016/B9780-444-62627-1.00020-2

13. Hartvigsen J, Frederiksen H, Christensen K. Back and neck pain in seniors-prevalence and impact. Eur Spine J. 2006;15(6):802-806. doi:10.1007/s00586-005-0983-6

14. Mutubuki EN, Beljon Y, Maas ET, et al. The longitudinal relationships between pain severity and disability versus health-related quality of life and costs among chronic low back pain patients. Qual Life Res. 2020;29(1):275-287. doi:10.1007/s11136-019-02302-w

15. Hurwitz EL, Morgenstern H, Harber P, et al. A randomized trial of medical care with and without physical therapy and chiropractic care with and without physical modalities for patients with low back pain: 6-month follow-up outcomes from the UCLA low back pain study. Spine (Phila Pa 1976). 2002;27(20):2193-2204. doi:10.1097/00007632200210150-00002

16. Geneen LJ, Moore RA, Clarke C, Martin D, Colvin LA, Smith BH. Physical activity and exercise for chronic pain in adults: an overview of Cochrane Reviews. Cochrane Database Syst Rev. 2017;4(4):CD011279. Published 2017 Apr 24. doi:10.1002/14651858.CD011279.pub3
17. Nijs J, Mairesse O, Neu D, et al. Sleep Disturbances in Chronic Pain: Neurobiology, Assessment, and Treatment in Physical Therapist Practice. Phys Ther. 2018;98(5):325335. doi:10.1093/ptj/pzy020

18. Gerhart JI, Burns JW, Post KM, et al. Relationships Between Sleep Quality and Pain-Related Factors for People with Chronic Low Back Pain: Tests of Reciprocal and Time of Day Effects. Ann Behav Med. 2017;51(3):365-375. doi:10.1007/s12160-016-9860-2

19. Bahouq H, Allali F, Rkain H, Hajjaj-Hassouni $N$. Discussing sexual concerns with chronic low back pain patients: barriers and patients' expectations. Clin Rheumatol. 2013;32(10):1487-1492. doi:10.1007/s10067013-2299-y

20. Lima M, Ferreira AS, Reis FJJ, Paes V, Meziat-Filho N. Chronic low back pain and back muscle activity during functional tasks. Gait Posture. 2018;61:250-256. doi:10.1016/j.gaitpost.2018.01.021

21. Hasegawa T, Katsuhira J, Oka H, Fujii T, Matsudaira K. Association of low back load with low back pain during static standing. PLoS One. 2018;13(12):e0208877. Published 2018 Dec 18. doi:10.1371/journal.pone.0208877

22. Lupu AA, Ionescu EV, Iliescu MG, Almasan RE, Oprea C, Ion I, Iliescu DM. Effect of Techirghiol specific climate factors on the patients quality of life with degenerative lumbar pain. J Environ Prot Ecol, 2018; 19 (4): 1857

23. Iliescu MG, Lupu AA, Ionescu EV, Tica I, Almasan RE, Oprea C., Iliescu D.M. Water, nature, Techirghiol - long term therapeutic benefits using aquatic exercise for patients with degenerative low back pain. J Environ Prot Ecol. 2019; 20(3):1505-1516

24. Popa F.L, Iliescu M.G., Stanciu M., Georgeanu V. Rehabilitation in a case of severe osteoporosis with prevalent fractures in a patient known with multiple sclerosis and prolonged glucocorticoid therapy. Balneo and PRM Research Journal 2021, 451, 12 (3): 284-288, doi:10.12680/balneo.2021.451

25. Tica I, Lupu A, Botnarciuc M, Petcu L, Oprea C, Badiu RG, Iliescu DM, Ionescu EV, Tica VI; Iliescu MG. Brain Derived Neurotrophic Factor - a Marker for the Balneal Treatment of Chronic Low Back Pain? Rev.Chim.(Bucharest) 2019, 70(9): 3180 , doi:10.37358/RC.19.9.7511

26. Popa FL, Stanciu M, Bighea A, Berteanu M, Totoianu IG, Rotaru M. Decreased serum levels of sex steroids associated with osteoporosis in a group of Romanian male patients. Rev Romana Med Lab. 2016;24(1):75-82;. ISSN online: 2284-5623; ISSN-L: 1841-6624; doi:10.1515/rrlm2016-0014.

27. Iliescu DM, Micu SI, Ionescu C, Bulbuc I, Bordei P, Obada $\mathrm{B}$, Voinea F, Gheorghe E, Iliescu MG; Axial and para axial loading response evaluation on human cadaver harvested lumbar vertebral blocks: In vitro experiment with possible clinical implications for clinical practice. EXPERIMENTAL AND THERAPEUTIC MEDICINE 22: 1192, 2021, doi: 10.3892/etm.2021.10626

28. Iliescu DM, Bordei P, Ionescu EV, Albina S, Oprea C, Obada B, Lupu AA, Hangan TL, Iliescu MG. Anatomicimaging Correlations of Lumbar Disk- vertebral Morphometric Indices. Int J Morphol, 2017; 35 (4), 1553, doi:10.4067/S0717-95022017000401553 